\title{
Individualized dual antiplatelet therapy based on platelet function testing in patients undergoing percutaneous coronary intervention: a meta-analysis of randomized controlled trials
}

\author{
Yijiang Zhou ${ }^{1+}$, Yanwei Wang ${ }^{2+}$, Yutao Wu' ${ }^{1}$, Chaoyang Huang ${ }^{1}$, Hui Yan ${ }^{1}$, Weiguo Zhu' ${ }^{1}$, Weiwei Xu' ${ }^{3}$, \\ Li Zhang $^{1 *}$ and Jianhua Zhu ${ }^{1 *}$ (D)
}

\begin{abstract}
Background: High on-treatment platelet reactivity (HPR) represents a strong risk factor for thrombotic events after $\mathrm{PCI}$. We aim to evaluate the efficacy and safety of individualizing intensified dual antiplatelet therapy (DAPT) in PCl-treated patients with HPR based on platelet function testing (PFT).

Methods: Electronic databases were searched for randomized control trials that reported the clinical outcomes of using an intensified antiplatelet protocol with $\mathrm{P}_{2} \mathrm{Y}_{12}$ receptor inhibitor comparing with standard maintenance dose of clopidogrel on the basis of platelet function testing. Clinical endpoints were assessed.

Results: From 2005 to 2016, thirteen clinical studies comprising 7290 patients were included for analysis. Compared with standard antiplatelet therapy with clopidogrel, the intensified protocol based on platelet function testing was associated with a significant reduction in major adverse cardiovascular events (RR:0.55, 95\% Cl: 0.36-0.84, $p=0.005$ ), cardiovascular death (RR:0.60, 95\% Cl: 0.38-0.96, $p=0.03$ ), stent thrombosis (RR:0.58, 95\% Cl: 0.36-0.93, $p=0.02$ ) and target vessel revascularization (RR:0.33, 95\% Cl: $0.14-0.76, p=0.009$ ). No significant difference was found in the rate of bleeding events between intensified and standard protocol.

Conclusions: Compared with standard clopidogrel therapy, individualized intensified antiplatelet therapy on the basis of platelet reactivity testing reduces the incidence of cardiovascular events in patient undergoing PCl, without increasing the risk of bleeding.
\end{abstract}

Keywords: Clopidogrel, Dual antiplatelet therapy, Percutaneous coronary intervention, High on-treatment atelet reactivity

\section{Background}

Dual antiplatelet therapy (DAPT) with aspirin and a $\mathrm{P}_{12} \mathrm{Y}_{12}$ antagonist represents the standard of care in patients with acute coronary syndrome (ACS) and those undergoing percutaneous coronary interventions (PCI) [1]. However, a concerning issue is that wide interindividual variability exists among $\mathrm{P}_{2} \mathrm{Y}_{12}$ antagonist,

\footnotetext{
* Correspondence: li.zhang.uk@gmail.com; zjh_john@medmail.com.cn ${ }^{\dagger}$ Equal contributors

'Department of Cardiology, The First Affiliated Hospital, Zhejiang University, School of Medicine, 79 Qingchun Road, Zhejiang, Hangzhou 310003, China

Full list of author information is available at the end of the article
}

especially clopidogrel [2-4]. The incidence of high ontreatment platelet reactivity (HPR) can be as high as in one-third of patients treated with clopidogrel, and HPR is present even in those receiving the more potent $\mathrm{P}_{2} \mathrm{Y}_{12}$ antagonists ticagrelor and prasugrel [5]. Numerous studies have demonstrated that HPR is associated with increased cardiovascular death and thrombotic events $[6,7]$. Several small clinical studies have shown that increasing the dose of clopidogrel or switching to a more potent $\mathrm{P}_{2} \mathrm{Y}_{12}$ receptor inhibitor in patients with HPR can significantly reduce the incidence of major adverse cardiac events (MACE) [8-10]. However, large 
randomized trials failed to demonstrate similar improvements in clinical outcomes with a tailored antiplatelet therapy based on platelet function monitoring [11-14]. Therefore, though some studies found platelet reactivityguided antiplatelet therapy to be beneficial in certain clinical endpoints like bleeding and stent thrombosis [15], the usefulness of tailored antiplatelet therapy during PCI is still controversial. In the present study, we performed meta-analysis on previous studies to evaluate the clinical efficacy and safety of individualized intensification of antiplatelet therapy with $\mathrm{P}_{2} \mathrm{Y}_{12}$ inhibitors versus standard dose clopidogrel on the basis of platelet function testing(PFT) in patients undergoing PCI.

\section{Methods}

PubMed, MEDLINE and ClinicalTrials were searched for clinical studies published between January 2005 and September 2016. The key words we used included the following terms: 'platelet function', 'platelet reactivity', 'platelet aggregation,' 'platelet aggregometry,' 'antiplatelet resistance, high on treatment platelet reactivity, $\mathrm{P} 2 \mathrm{Y}_{12}$-ADP receptor inhibitor,' 'clopidogrel,' 'prasugrel,' 'ticagrelor' and 'percutaneous coronary intervention'. In addition, references of relevant studies and reviews, editorials, and letters, together with related conference abstracts were also searched.

The main criteria for inclusion in this analysis were trials that compared clinical efficacy and/or safety of an intensified antiplatelet therapy with that of standarddose clopidogrel therapy on the basis of platelet reactivity testing in patients undergoing PCI. Studies without platelet function testing were excluded. Similarly, studies that compared only the pharmacological efficacy of a platelet function-guided anti-platelet therapy were also excluded. Moreover, studies in which platelet inhibitor other than $\mathrm{P}_{2} \mathrm{Y}_{12}$ inhibitors were used were excluded.

According to international consensus and previous studies [16, 17],the accepted ADP-specific platelet function devices were: (a) VerifyNow $\mathrm{P}_{12} \mathrm{Y}_{12}$ assay, (b) Multiplate analyzer with ADP test, (c) Flow cytometric assessment of vasodilator stimulated phosphoprotein (VASP) phosphorylation index, and (d) Conventional light transmission aggregometry (LTA).

The efficacy endpoints of the analysis included: (a) Major adverse cardiovascular events (MACE), (b) Cardiovascular death, (c) Definite/probable ST, (d) Myocardial infarction (MI), (e) Stroke and (f) Target vessel revascularization (TVR). All of them were defined according to the study definition. In particular, MACE was primarily defined as a composite of cardiovascular death, myocardial infarction and definite/probable stent thrombosis, though a few studies also included endpoint of stroke or transient ischemic attack (TIA). The main safety endpoint was major bleeding and major or minor bleeding events, which were defined according to the study definition,including BARC, TIMI, GUSTO and STEEPLE [18-21]. The net clinical end point was defined as a composite of MACE and major bleeding.

Two investigators independently assessed reports for eligibility on the title and/or at abstract level, with divergences resolved with a third reviewer; studies that met inclusion criteria were selected for further analysis. The risk of bias was evaluated by the same two reviewer authors, in accordance with The Cochrane Collaboration methods [22].

Meta-analysis was performed using the Review Manager 5.3 and STATA 14 statistical software. Reported event frequencies were used to calculate risk ratios (RR) with $95 \%$ confidence intervals $(\mathrm{CI})$. Heterogeneity of the trial results was quantified with the $\mathrm{Chi}^{2}$ heterogeneity statistic, with inconsistency assessed by means of $\mathrm{I}^{2}$. Results were reported as the $p$ value of the $\mathrm{Chi}^{2}$ test $(p<0.05$ for heterogeneous results) and percentage of the $\mathrm{I}^{2}$. Interpretation of the latter was made by assigning attributes of low, moderate, and high in case of $0-25 \%$, $50-75 \%$ and more than $75 \%$, respectively. We used a random-effects or a fixed-effect model based on degree of heterogeneity. The random-effects model results in wider confidence intervals and provides more conservative and robust results, and it was used when $\mathrm{I}^{2}>50 \%$. Subgroup analyses were performed according to strategies to overcome HPR, intervention duration, follow-up duration and method of platelet function testing. Analysis of variance(ANOVA) were further carried out between different subgroups. To determine the impact of baseline risks and study characteristics on the MACE and net clinical benefit, meta-regression analyses were performed with STATA 14 software. To study the relevance of publication bias, funnel plots were constructed plotting the trial results against their precision. Begg's regression intercept was used to assess asymmetry of these funnel plots. Only composite clinical endpoints were used from the metaanalysis. The Duval and Tweedie's "Trim and Fill" method was used to impute 'hypothetical' missing studies and to calculate adjusted versus observed RRs.

\section{Results}

Through searching with aforementioned key words, 3466 reports were retrieved, of which 2239 relevant publications were identified at the abstract and title level. Full text assessment was performed in 32 trials. By applying the inclusion and exclusion criteria, thirteen studies involving 7290 (range: 60-2440) patients were qualified for the analysis (Fig. 1). A summary table of review authors' judgements for each risk of bias item for each study was shown in Fig. 2. The detailed characteristics of the included studies are shown in Table 1. Studies vary according to publication year, risk profiles of the 


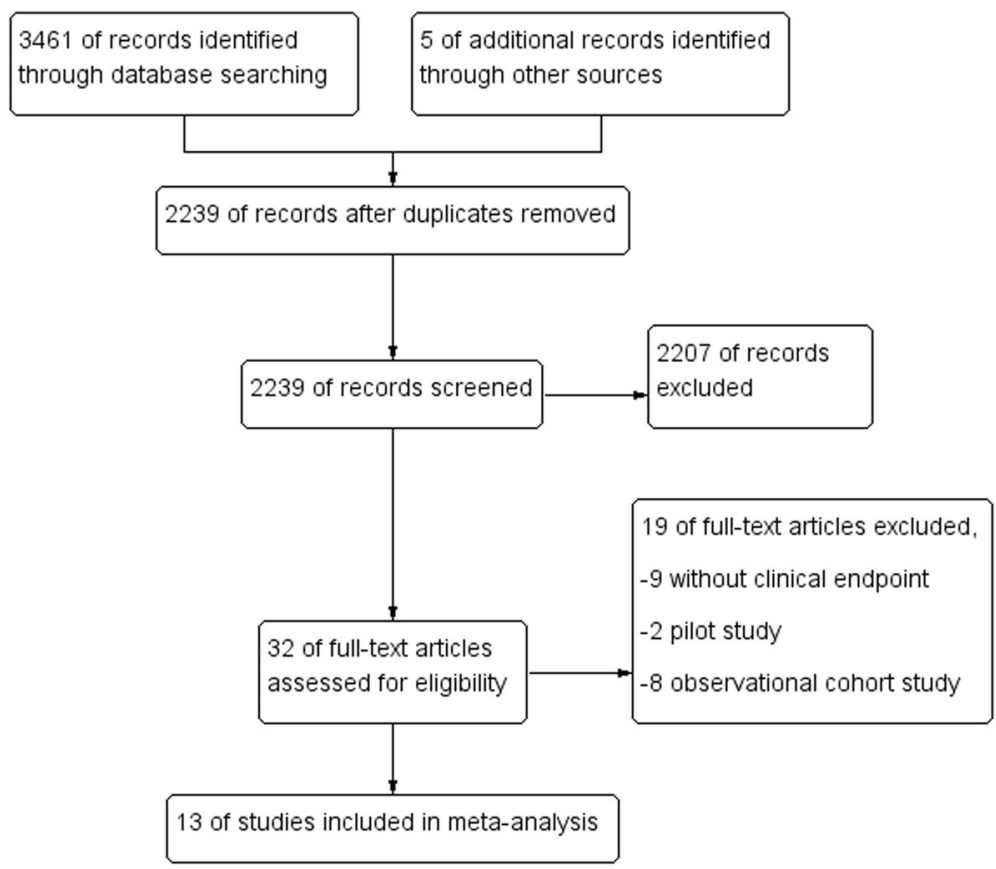

Fig. 1 Flowchart of study selection

recruited patients, platelet function assay used, definition of HPR, intensified antiplatelet strategy applied and clinical endpoints. All studies used $\mathrm{P}_{2} \mathrm{Y}_{12}$ antagonist for intensified antiplatelet regime: two studies administered repeated loading dose of $600 \mathrm{mg}$ clopidogrel [8, 9]; seven studies increased maintenance dose of clopidogrel [11, 23-28]; two studies used repeated loading dose of $600 \mathrm{mg}$ clopidogrel combined with increased maintenance dose of clopidogrel or prasugrel [29, 30]; another two studies used prasugrel for loading and maintenance [13, 14].

Based on the pooled results, the intensified therapy was associated with a significant reduction in major adverse cardiovascular events (MACE) (RR: 0.55, 95\% CI: 0.36$0.84, p=0.005$; Fig. 3). Moreover, intensified antiplatelet strategy guided by platelet function testing reduced rate of cardiovascular death (RR: 0.60, 95\% CI: 0.38-0.96, $p=0.03$ ), definite/probable stent thrombosis (RR: 0.58, 95\% CI: 0.36-0.93, $p=0.02)$ and target vessel revascularization (TVR) (RR: 0.33, 95\% CI: 0.14-0.76, $p=0.009$ ) (Figs. 4a-c). On the other hand, there was no difference in incidence of death from any cause (RR: 0.95, 95\% CI: $0.65-1.39, p=0.81$ ) or myocardial infarction (RR: 1.02 , 95\% CI: $0.91-1.15, p=0.74$ ) between platelet functionguided intensified antiplatelet strategy with standard maintenance dose of clopidogrel therapy (Fig. 4d-e).

No difference in the rate of major bleeding events (RR: $0.75,95 \%$ CI: $0.54-1.03, p=0.08$ ) or major or minor bleeding events (RR: $1.04,95 \%$ CI: $0.88-1.23$, $p=0.67)$ was observed between the two therapeutic groups (Fig. 5).
The net clinical benefit, consisting of both thrombotic and bleeding events, was also superior in intensified therapy (RR: 0.67, 95\% CI: 0.49-0.93, $p=0.02)$ (Fig. 6).

Subgroup analyses were performed. According to strategies to overcome HPR (repeated clopidogrel loading, increased clopidogrel maintenance dose or switching to prasugrel), pooled results showed that repeated loading or increased maintenance dose of clopidogrel significantly reduced the incidence of MACE without increasing major bleeding events, favoring a net clinical benefit. However, switching to prasugrel was similar with standard therapy in MACE, major bleeding and net clinical benefit. Pooled results from trials with intervention duration of 1 month or less and follow-up time of 1 month showed that intensified antiplatelet strategy significantly decreased the MACE, cardiovascular death and net clinical events. Results from studies using VASP showed that intensified therapy was associated with less incidence of MACE, cardiovascular death and net clinical events (Table 2). ANOVA analyses were also performed between subgroups according to strategies to overcome HPR, intervention duration, follow-up duration and platelet function testing, showing that differences across subgroups in MACE and net clinical events are significant (Table 2). What's more, pooled result from studies only included patients with stable coronary artery disease showed that intensified therapy decreased the incidence of MACE (RR: $0.23,95 \% \mathrm{CI}: 0.09-0.60$, $p=0.002$ (Additional file 1). 


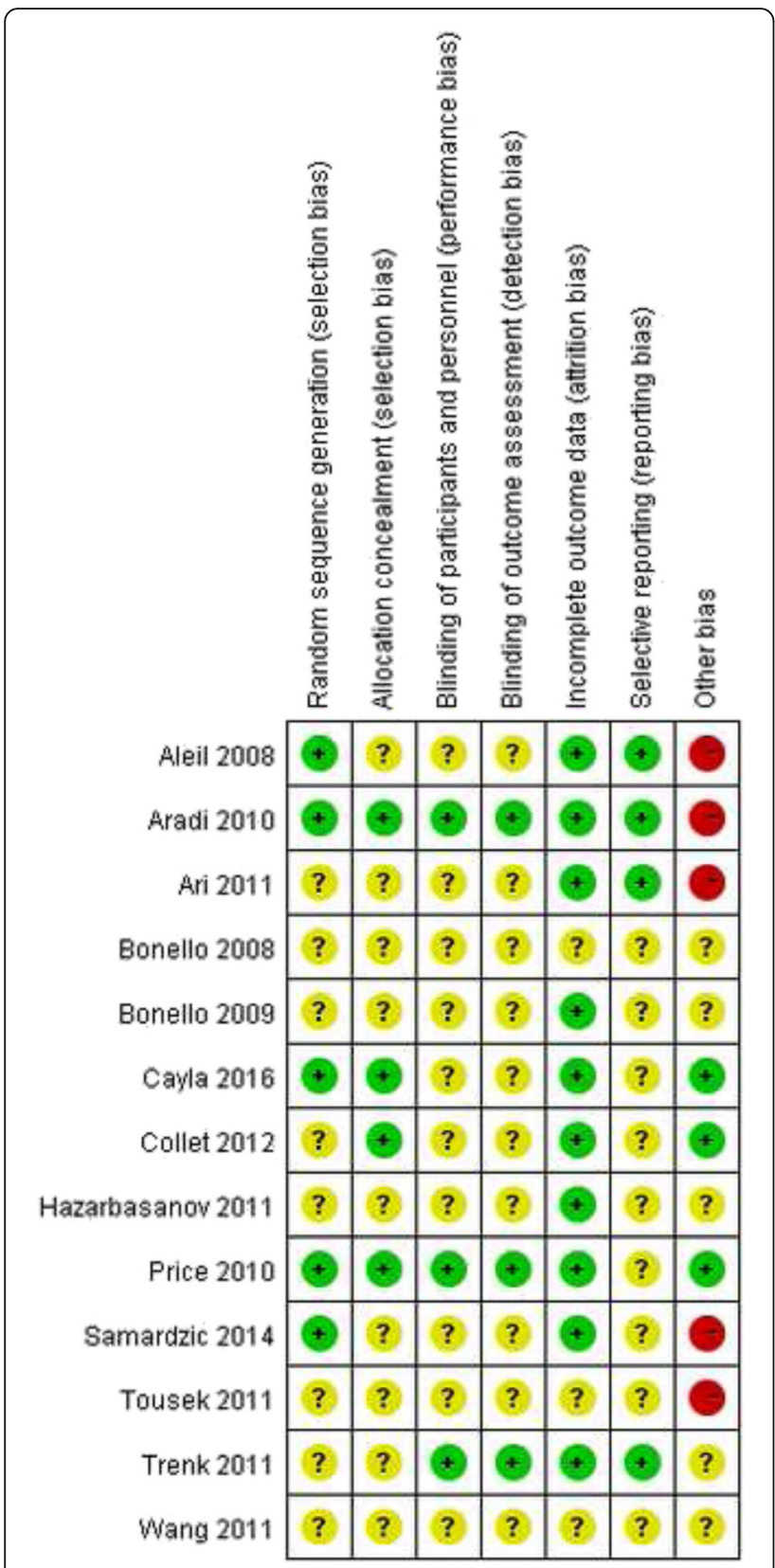

Fig. 2 Summary table of review authors' judgements for each risk of bias item for each study

To evaluate the impact of baseline clinical risks and study characteristics on the MACE and net clinical benefit of the individualized therapy, we performed meta-regression for different variables, including percentage of ACS patients, study size, patient age, cut-off value for HPR, follow-up time ( $\leq 1$ months or $>1$ months) and intervention duration ( 1 month, 6 months or 12 months) (Table 3). Our analysis showed that study size and intervention duration were significantly associated MACE, and the above two factors as well as followup time were associated with net clinical benefit, suggesting the heterogeneity in clinical efficacy were partially explained by these factors .

To check for the possibility of a publication bias, we used Begg's test and found no publication bias in cardiovascular death $(p=0.536)$, definite/probable ST $(p=0.108)$, myocardial infarction $(p=0.386)$, MACE $(p=0.583)$, major bleeding $(p=0.175)$ and net clinical benefits $(p=0.350)$. Furthermore, sensitivity analysis by Trim and Fill method showed that the pooled results of MACE and net clinical benefits were reliable.

\section{Discussion}

The results our meta-analysis showed that in patients undergoing PCI with HPR, a strategy of individualized intensification of dual antiplatelet therapy reduces adverse cardiovascular events, including cardiovascular death, stent thrombosis and target vessel revascularization, without increasing hemorrhagic complications.

Dual antiplatelet therapy with aspirin and $\mathrm{P}_{2} \mathrm{Y}_{12}$ antagonists has become the standard therapy for preventing adverse cardiovascular events after PCI. However, considerable inter-individual variability exists among patients receiving clopidogrel. Many observational studies have established HPR as the risk factor for ischemic events after PCI, but whether modifying HPR with intensified antiplatelet regime can improve cardiovascular outcome is still controversial. AHA/ACC guidelines of PCI recommend that in patients at high risk of stent thrombosis, platelet aggregation test may be applied, and that if platelet inhibition is inadequate, clopidogrel dose may be increased [31, 32]. Since the prognostic value of bleeding complications is equally important as ischemic events, a personalized approach to tailor the antiplatelet therapy for patients with variable on-treatment platelet reactivity is an attractive strategy. Though small clinical trials have demonstrated that increasing the dose of clopidogrel in patients with HPR can reduce the incidence of major adverse cardiac events, some large randomized trials failed to demonstrate an improvements in clinical outcomes with a tailored anti-platelet therapy based on platelet-function monitoring $[11,13,29]$. The small number of events in low risk patients included in these trials might be accountable for negative results. Moreover, poor responsiveness is likely due to multifactorial reasons, including clinical, cellular and genetic factors, with gene polymorphisms emerging as one of the major determinants of clopidogrel response [33-35]. Different mutations may lead to discrepant gene function, therefore resulting in poor to no clopidogrel response. Intensified anti-platelet regime used in these trials might overcome certain types of mutations, but could not achieve sufficient platelet inhibition in patients with specific genotype. What's more, recent studies demonstrated that the magnitude of the association between 
Table 1 Study characteristics

\begin{tabular}{|c|c|c|c|c|c|c|}
\hline Author & Acronym & Date & Blinding & Patient no. (tailored/control) & Platelet function assay & HPR cut-off \\
\hline Aleil & & 2008 & No & $31 / 62$ & VASP & VASP-PRI > 69\% \\
\hline Bonello & & 2008 & No & $78 / 84$ & VASP & VASP-PRI > 50\% \\
\hline Bonello & & 2009 & No & $215 / 214$ & VASP & VASP-PRI > 50\% \\
\hline Aradi & DOSER & 2010 & Yes & $36 / 38$ & LTA, $5 \mu \mathrm{M}$ ADP & >34\%AGGmax \\
\hline Price & GRAVITAS & 2010 & No & $1109 / 1105$ & VerifyNow,P2Y12 & $>230 P R U$ \\
\hline Ari & EFFICIENT & 2011 & Yes & $47 / 47$ & VerifyNow P2Y12 & $<40 \%$ inhibition \\
\hline Hazarbasanov & & 2011 & No & 97/95 & VerifyNow P2Y12 & $>208$ PRU \\
\hline Tousek & & 2011 & No & $30 / 30$ & VerifyNow P2Y12 & $>240 \mathrm{PRU}$ \\
\hline Trenk & TRIGGER-PCI & 2011 & Yes & $212 / 211$ & VerifyNow P2Y12 & $>208$ PRU \\
\hline Wang & & 2011 & No & $150 / 156$ & VASP & VASP-PRI > 50\% \\
\hline Collet & ARCTIC & 2012 & No & $1213 / 1227$ & VerifyNow,P2Y12 & $>235 P R U$ \\
\hline Samardzic & & 2014 & No & $43 / 44$ & MEA & $>46 \mathrm{U}$ \\
\hline Cayla & ANTARCTIC & 2016 & No & $435 / 442$ & VerifyNow,P2Y12 & $>208$ PRU \\
\hline Author & \multicolumn{2}{|l|}{ Clinical setting } & \multicolumn{2}{|c|}{ Modified treatment } & Intervention duration & Follow-up \\
\hline Aleil & \multicolumn{2}{|c|}{ Scheduled for elective coronary stenting } & \multicolumn{2}{|c|}{150 mg MD clopidogrel } & 2 weeks & 1 month \\
\hline Bonello & \multicolumn{2}{|c|}{ Stable angina:52\% NSTEMI:48\% STEMI: 0\% } & \multicolumn{2}{|c|}{ Repeated 600 mg clopidogrel LD } & One week & 30 days \\
\hline Bonello & \multicolumn{2}{|c|}{ Stable angina:48\% NSTEMI:52\% STEMI: 0\% } & \multicolumn{2}{|c|}{ Repeated 600 mg clopidogrel LD } & One week & 30 days \\
\hline Aradi & \multicolumn{2}{|c|}{ Stable angina:100\% } & \multicolumn{2}{|c|}{600 mg LD +150 mg MD clopidogrel } & 1 month & 12 months \\
\hline Price & \multicolumn{2}{|c|}{ Stable angina:60\% NSTEMI:10.1\% STEMI: 0.4\% } & \multicolumn{2}{|c|}{600 mg LD +150 mg MD clopidogrel } & 6 months & 6 months \\
\hline Ari & \multicolumn{2}{|c|}{ Stable angina:100\% } & \multicolumn{2}{|c|}{150 mg MD clopidogrel } & 1 month & 6 months \\
\hline Hazarbasanov & \multicolumn{2}{|c|}{ Stable angina:43\% NSTEMI:33\% STEMI: 24\% } & \multicolumn{2}{|c|}{600 mg LD +150 mg clopidogrel } & 1 month & 6 months \\
\hline Tousek & \multicolumn{2}{|c|}{ Stable angina:23\% NSTEMl:34\% STEMI: 43\% } & \multicolumn{2}{|c|}{$\begin{array}{l}\text { clopidogrel starting at } 150 \mathrm{mg} / \text { day } \\
\text { with further dose increase }\end{array}$} & 1 month & 6 months \\
\hline Trenk & \multicolumn{2}{|c|}{ Stable angina:100\% } & \multicolumn{2}{|c|}{60 mg LD +10 mg MD Prasugrel } & 6 months & 6 months \\
\hline Wang & \multicolumn{2}{|c|}{ Stable angina:80\% NSTEMI:20\% STEMI: 0\% } & \multicolumn{2}{|c|}{$\begin{array}{l}\text { increase in clopidogrel MD up to } \\
375 \mathrm{mg}\end{array}$} & 11 months & 1 year \\
\hline Collet & \multicolumn{2}{|c|}{ Scheduled for elective coronary stenting } & \multicolumn{2}{|c|}{$\begin{array}{l}\text { Repeated } 600 \text { mg clopidogrel LD + } \\
150 \text { mg MD clopidogrel/10 mg MD } \\
\text { Prasugrel }\end{array}$} & 12 months & 12 months \\
\hline Samardzic & \multicolumn{2}{|c|}{ Stable angina:16\% NSTEMI:23\%STEMI:60\% } & \multicolumn{2}{|c|}{$\begin{array}{l}\text { up to clopidogrel } 600 \mathrm{mg} \times 2+ \\
\text { (75-300 mg MD) }\end{array}$} & 12 months & 12 months \\
\hline Cayla & \multicolumn{2}{|c|}{ Stable angina:18\% NSTEMI:48\%STEMI:34\% } & \multicolumn{2}{|c|}{ 5-10 mg MD Prasugrel } & 12 months & 12 months \\
\hline
\end{tabular}

Abbreviations ACS acute coronary syndrome, CV cardiovascular, HTPR high on-treatment platelet reactivity, $L D$ loading dose, MD maintenance dose, MI myocardial infarction, STEMI ST-segment elevation myocardial infarction, NSTEMI non-ST segment elevation myocardial infarction, ST stent thrombosis, TVR target vessel revascularization, $M A C E$ major adverse cardiovascular events $R C T$ randomized, controlled trial

HPR on clopidogrel treatment and incidence of MACE is strongly dependent on the level of patients' cardiovascular risk [36].

Previously published meta-analysis on intensified antiplatelet therapy on the basis of platelet reactivity testing suggested that in patients undergoing PCI who have HPR, more potent antiplatelet regime reduced the rate of thrombotic events without increasing the risk for bleeding events [37, 38]. But these studies synthesized different classes of antiplatelet agents, including periprocedural use of glycoprotein IIb/IIIa receptor inhibitors (GPIs). Our study focused on dual antiplatelet therapy with aspirin and $\mathrm{P}_{2} \mathrm{Y}_{12}$ antagonists only, since we believe with broader application of newer $\mathrm{P}_{2} \mathrm{Y}_{12}$ inhibitors, procedural use of GPI would be gradually decreasing. Our results clearly showed that individualized intensification of dual anti-platelet therapy reduced adverse cardiovascular events,which might mainly derive from the decreasing of cardiovascular death, stent thrombosis and target vessel revascularization, leading to net clinical benefit.

From our subgroup analysis, we found strategy of overcoming HPR had a major impact on clinical efficacy. While repeated loading or increased maintenance dose of clopidogrel significantly reduced incidence of MACE and favored net clinical benefit, it is intriguing to find 


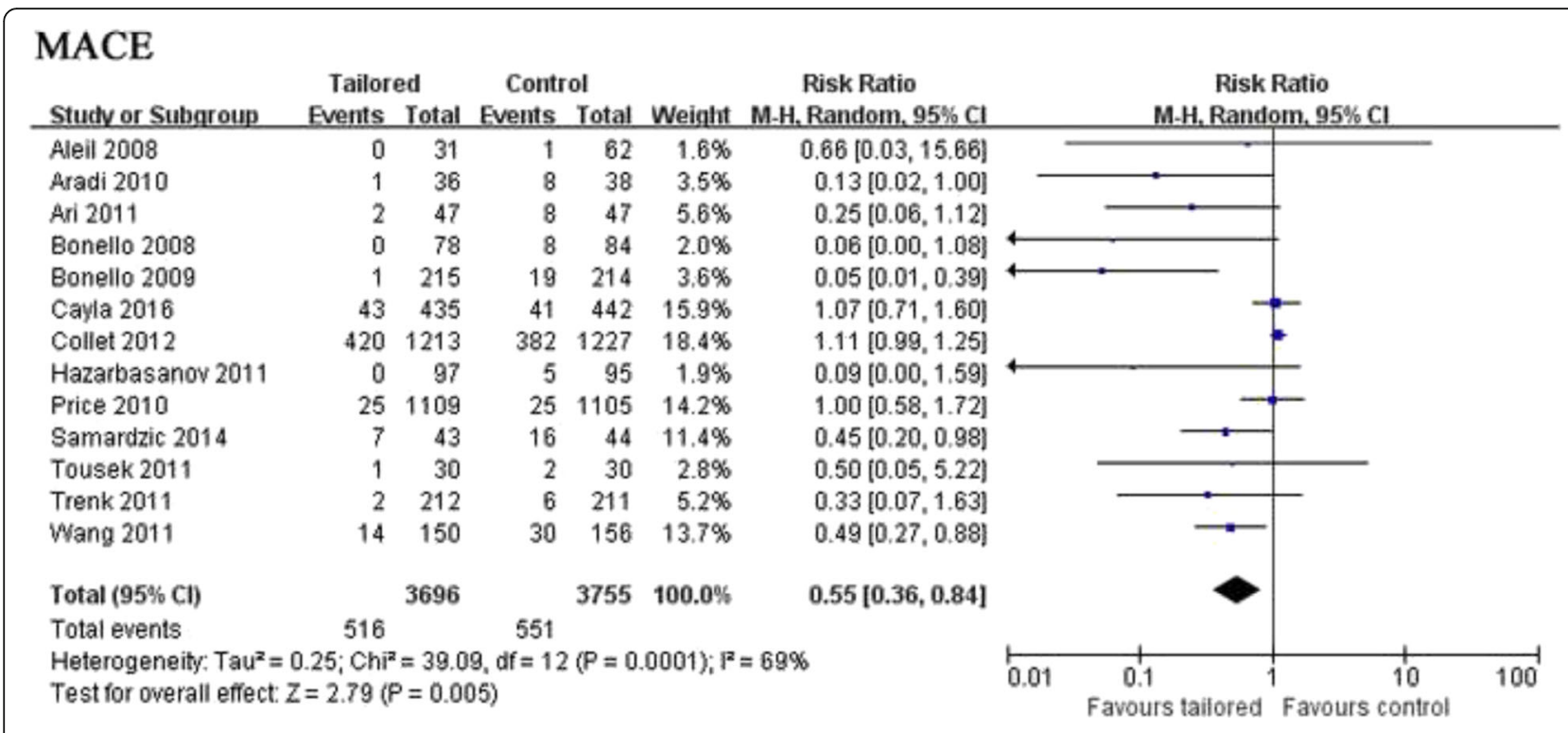

Fig. 3 Forest plot for incidence of major adverse cardiovascular events. Risk ratio for individual studies (squares) and meta-analysis (diamonds) and $95 \% \mathrm{Cl}$ (horizontal lines) are presented

the newer $\mathrm{P}_{2} \mathrm{Y}_{12}$ inhibitors prasugrel did not. Though the reason remained unknown, possible explanations are: 1) number of studies that used prasugrel (only TRIGGER-PCI and ANTARCTIC study) is far less than those used higher doses of clopidogrel, potentially biasing the result; 2) TRIGGER-PCI study included patients at low ischemic rate, possibly masking the benefit of prasugrel; 3) ANTARCTIC study only enrolled patients of 75 years or older, its failure to demonstrate the benefit of prasugrel is limited to this sub-population. Whether PFT-based prasugrel dosing could reduce ischemic event in a broader patient population with higher risks needs further investigation. It would also be interesting test another new P2Y12 inhibitor, ticagrelor. Our analysis and meta-regression analysis also showed studies with short intervention duration ( $\leq 1$ month) and follow-up time (1 month) were more beneficial than those with longer intervention or follow-up duration in the endpoints of MACE, cardiovascular death and net clinical events. It seems reasonable that the PFT-guided anti-platelet therapy is prone to reduce shorter-term cardiovascular events, since platelet function testing are mostly performed peri-procedurally and reflects peri-procedural thrombotic burden. It is also interesting from our analysis that considering studies using only Verifynow, such strategy did not reduce any cardiovascular outcomes, as opposed to VASP. One reason is that studies using Verifynow adopted different thresholds for HPR, ranging from $>208$ PRU to $>240$ PRU. Also possible is that VerifyNow-P2Y12 cartridge might be influenced by many factors such as time between process, platelet count, hematocrit and etc. However, whether VASP is indeed better than VerifyNow in guiding individualized DAPT needs further study.

Previous studies reported inconsistent results in the relationship between HPR and bleeding. Sibbing et al. showed that patients with and without HPR had similar incidence of major and minor bleeding [4]. However, ADAPT-DES trial found that HPR was inversely related to bleeding events [39]. Evidence is still lacking in applying PFT to estimate bleeding risk. In our study, we found no difference in bleeding events between two groups, indicating only the safety of PFT-based intensified antiplatelet therapy.

Newly developed P2 $\mathrm{Y}_{12}$ inhibitors prasugrel and ticagrelor are more potent and have a faster onset of action than clopidogrel, making them particularly attractive for patients undergoing PCI. In ACS patients exhibiting HPR on clopidogrel after PCI, both ticagrelor and prasugrel provide effective and sufficient platelet inhibition [40]. Studies have demonstrated that in patients with HPR, switching to prasugrel achieved adequate platelet inhibition and reduced thrombotic events [41, 42]. With increasing usage of newer $\mathrm{P}^{2} \mathrm{Y}_{12}$ inhibitors for coronary intervention, it may seem less necessary to concern about platelet resistance. However, there are still several issues unsettled. A proportion of patients treated with new $\mathrm{P}_{2} \mathrm{Y}_{12}$ inhibitors still display HPR, particularly during acute phase of myocardial infarction, putting forward an issue of how to deal with these non-responders. More importantly, new $\mathrm{P}_{2} \mathrm{Y}_{12}$ inhibitors carry an increased bleeding risk, so it would be challenging to tailor these agents with a balance between ischemic events and hemorrhagic complications. Platelet function testing 

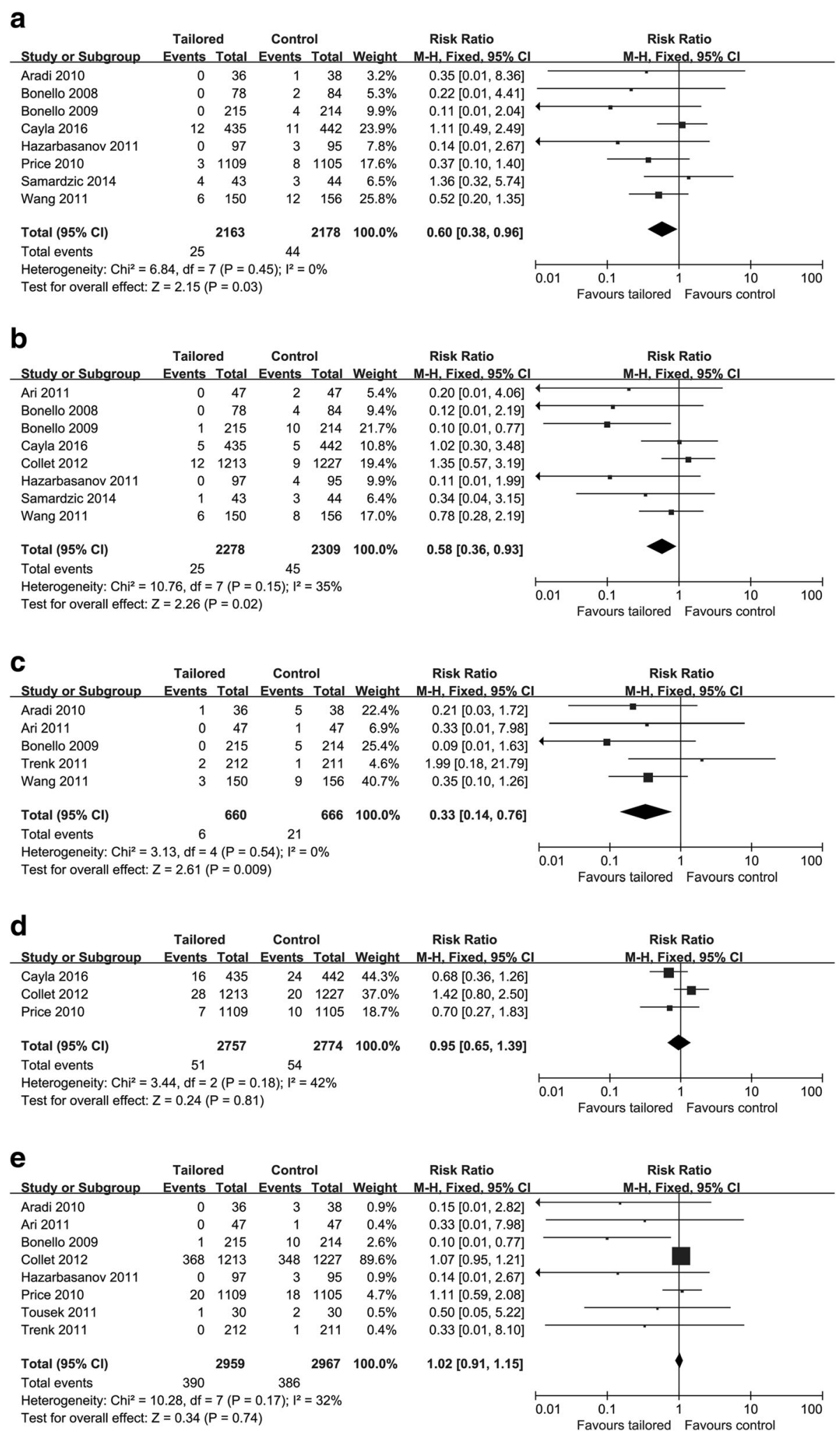

Fig. 4 Forest plot for incidence of cardiovascular death, a stent thrombosis $\mathbf{b}$, target vessel revascularization, $\mathbf{c}$ death $\mathbf{d}$ and myocardial infarction e. Risk ratio for individual studies (squares) and meta-analysis (diamonds) and 95\% Cl (horizontal lines) are presented 


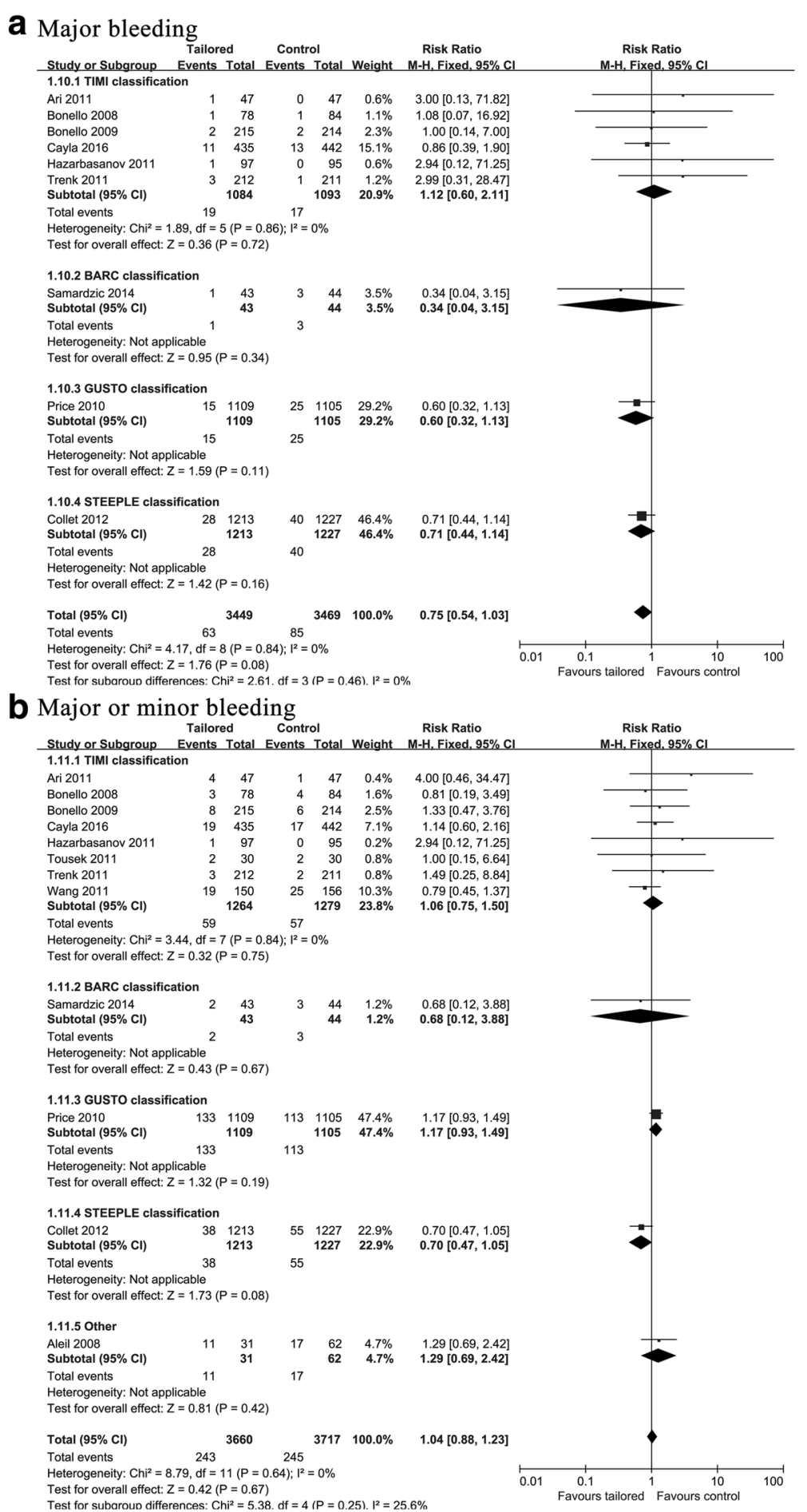

Fig. 5 Forest plot for incidence of major bleeding $\mathbf{a}$ and major or minor bleeding $\mathbf{b}$. Risk ratio for individual studies (squares) and meta-analysis (diamonds) and 95\% Cl (horizontal lines) are presented

may help sort out patients with benefit/risk ratio favorable for more potent anti-platelet therapy. As indicated in our analysis, the individualized approach based on PFT can improve net clinical benefit and should be considered to guide anti-platelet regime in future practice.
Still, an appropriate defining of therapeutic window based on different methods of PFT needs further investigation to optimize intensified anti-platelet therapy.

It is noteworthy that our study included target vessel revascularization in the endpoint. The rationale of 


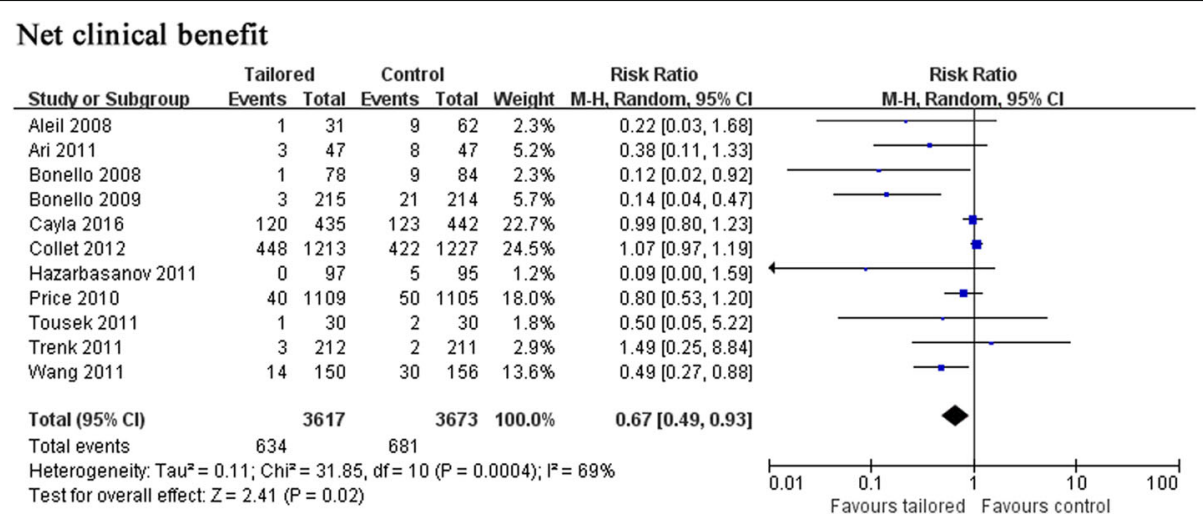

Fig. 6 Forest plot for incidence of net clinical benefit. Risk ratio for individual studies (squares) and meta-analysis (diamonds) and 95\% Cl (horizontal lines) are presented

incorporating TVR in our analysis was that several studies have demonstrated a significant increase in revascularization rate in patients with HPR [43, 44]. More importantly, though still controversial, the notion that intensified antiplatelet therapy may have an inhibitory effect upon instent restenosis has been supported by some studies. For example, the DECLARE study series showed that cilostazol-based triple antiplatelet therapy could reduce angiographic restenosis and target lesion revascularization $[45,46]$. Experimental research also indicated that the more potent ticagrelor could effectively inhibit neointima formation and potentially reduce restenosis [47]. Furthermore, the recent TRANSLATE-ACS study showed that switching clopidogrel to prasugrel led a significant decrease in unplanned revascularization rate [44]. In agreement with above findings, our pooled result also revealed association between intensified P2Y12 inhibition and reduction of TVR. However, since current level of evidence is still low, further study is needed to confirm whether more potent anti-platelet regime would decrease in-stent restenosis and incidence of TVR.

Our study has several limitations that should be taken into account. First, since there is no general agreement on standard definition of platelet resistance, studies included in our analysis used different definitions of platelet resistance or non-responsiveness. Defining HPR also varies according to the method of PFT, though there is an adequate correlation between different tests [48]. Since HPR cutoff values reported in many studies are associated with high negative predictive values and low

Table 2 Subgroup analysis

\begin{tabular}{|c|c|c|c|c|c|c|c|c|c|c|c|c|}
\hline & \multicolumn{3}{|l|}{ MACE } & \multicolumn{3}{|c|}{ Cardiovascular death } & \multicolumn{3}{|l|}{ Major bleeding } & \multicolumn{3}{|c|}{ Net clinical events } \\
\hline & $\mathrm{RR}(95 \% \mathrm{Cl})$ & $1^{2}(\%)$ & $p$ & $\mathrm{RR}(95 \% \mathrm{Cl})$ & $1^{2}(\%)$ & $p$ & $\mathrm{RR}(95 \% \mathrm{Cl})$ & $\mathrm{I}^{2}(\%)$ & $p$ & $\mathrm{RR}(95 \% \mathrm{Cl})$ & $\mathrm{I}^{2}(\%)$ & $p$ \\
\hline \multicolumn{3}{|c|}{ Strategies to overcome HPR } & 0.02 & & & 0.26 & & & 0.60 & & & $<0.001$ \\
\hline Repeated LD & $0.06(0.01-0.29)$ & 0 & $<0.001$ & $0.15(0.02-1.18)$ & 0 & 0.07 & $1.02(0.21-5.02)$ & 0 & 0.98 & $0.14(0.05-0.38)$ & 0 & $<0.001$ \\
\hline Increased MD & $0.56(0.39-0.96)$ & 66 & 0.003 & $0.41(0.20-0.84)$ & 0 & 0.01 & $0.69(0.38-1.25)$ & 0 & 0.22 & $0.59(0.44-0.81)$ & 10 & 0.001 \\
\hline Switch to prasugrel & $0.77(0.28-2.15)$ & 49 & 0.62 & & & & $1.01(0.49-2.11)$ & 5 & 0.97 & $1.00(0.81-1.24)$ & 0 & 1.00 \\
\hline \multicolumn{3}{|l|}{ Intervention duration } & $<0.001$ & & & 0.06 & & & 0.26 & & & $<0.001$ \\
\hline$\leq 1$ month & $0.16(0.07-0.37)$ & 0 & $<0.001$ & $0.17(0.04-0.75)$ & 0 & 0.02 & $1.51(0.43-5.34)$ & 0 & 0.52 & $0.21(0.11-0.42)$ & 0 & $<0.001$ \\
\hline$>1$ month & $0.81(0.58-1.14)$ & 65 & 0.23 & $0.75(0.45-1.25)$ & 6 & 0.27 & $0.71(0.51-0.99)$ & 0 & 0.05 & $0.93(0.75-1.14)$ & 54 & 0.47 \\
\hline \multicolumn{3}{|l|}{ Follow up duration } & 0.03 & & & 0.11 & & & 0.91 & & & $<0.001$ \\
\hline 1 month & $0.09(0.02-0.40)$ & 0 & 0.001 & $0.15(0.02-1.18)$ & 0 & 0.07 & $1.02(0.21-5.02)$ & 0 & 0.98 & $0.15(0.06-0.38)$ & 0 & $<0.001$ \\
\hline 6 months & $0.48(0.21-1.11)$ & 38 & 0.09 & $0.30(0.09-1.00)$ & 0 & 0.05 & $0.77(0.44-1.36)$ & 11 & 0.38 & $0.72(0.49-1.08)$ & 2 & 0.11 \\
\hline 12 months & $0.73(0.46-1.14)$ & 75 & 0.16 & $0.84(0.49-1.15)$ & 0 & 0.53 & $0.72(0.49-1.08)$ & 0 & 0.11 & $0.93(0.72-1.21)$ & 71 & 0.60 \\
\hline \multicolumn{3}{|l|}{ Platelet function device } & 0.05 & & & 0.27 & & & 0.72 & & & $<0.001$ \\
\hline VerifyNow & $0.94(0.70-1.27)$ & 37 & 0.69 & $0.69(0.37-1.32)$ & 39 & 0.26 & $0.76(0.54-1.05)$ & 0 & 0.10 & $0.98(0.82-1.16)$ & 26 & 0.79 \\
\hline VASP & $0.20(0.05-0.91)$ & 58 & 0.04 & $0.38(0.16-0.89)$ & 0 & 0.03 & $1.02(0.21-5.02)$ & 0 & 0.98 & $0.27(0.12-0.59)$ & 38 & 0.001 \\
\hline
\end{tabular}


Table 3 Meta-regression analyses for MACE and net clinical benefit

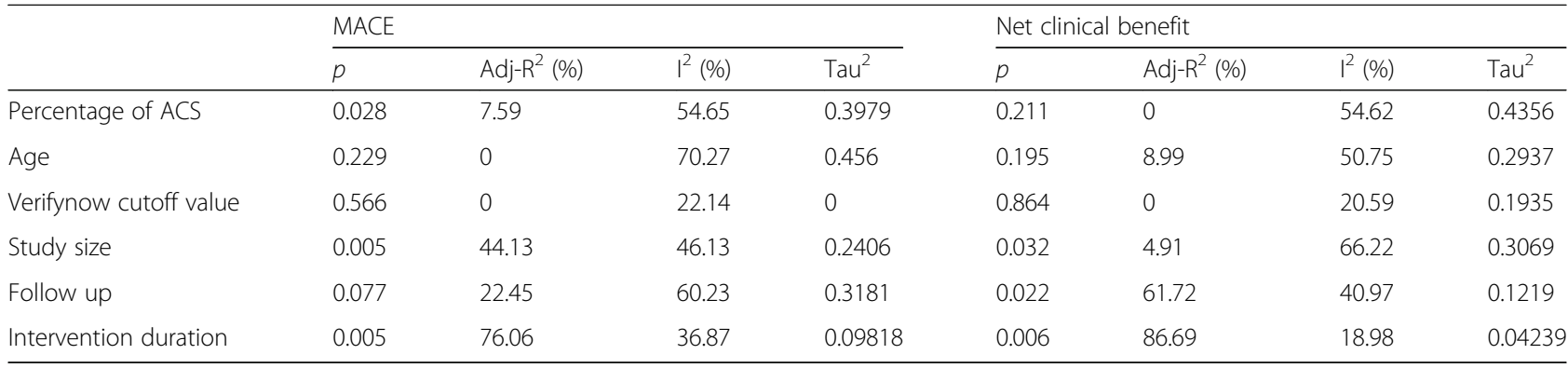

positive predictive values, it may have an impact on the pooled results. Second, while most studies defined MACE as composite of cardiovascular death, myocardial infarction and definite/probable stent thrombosis, three studies included stroke/TIA in MACE as well. However, due to low incidence of stroke/TIA in these studies, the difference in the definition of MACE across studies is unlikely to affect our pooled results. Third, trials included in our study used different strategies to overcome HPR, so the extent of platelet inhibition is not same. Tailored therapy like doubling the dose of clopidogrel may still be insufficient to repress platelet activity. Forth, risk profile of patients included in our study was different. Patients in high risk group tend to have higher cardiovascular events, which may also affect the pooled results. What's more, a small part of patients with low on-treatment reactivity were mixed in platelet function monitoring group in some studies, such as ARCTIC and ANTARCTIC trials. Such design may partly neutralize the benefit of tailored therapy, and have some affect in the pooled results.

\section{Conclusion}

In conclusion, the present meta-analysis from RCTs suggests that in patients undergoing PCI who have HPR based on platelet function testing, intensified dual antiplatelet therapy reduces the incidence of thrombotic events without increasing the risk of major bleeding compared with standard clopidogrel therapy.

\section{Additional file 1}

Additional file 1: Supplemental Material. (DOC 365 kb)

\footnotetext{
Abbreviations

ACS: Acute coronary syndrome; Cl: Confidence interval; HPR: High on-treatment platelet reactivity; MACE: Major adverse cardiovascular event; LD: Loading dose; MD: Maintenance dose; MI: Myocardial infarction; NSTEMI: Non-ST segment elevation myocardial infarction; RR: Risk ratio; PCl: Percutaneous coronary intervention; RCT: Randomized, controlled trial; ST: Stent thrombosis; STEMI: ST-segment elevation myocardial infarction; TVR: Target vessel revascularization; TIMI: Thrombolysis in Myocardial Infarction
}

\section{Acknowledgments}

The authors would like to thank Jessica M. Lee for her assistance in polishing the manuscript. The authors report no conflicts of interest. The authors alone are responsible for the content and writing of the paper.

Availability of data and materials

All data and material are allowed for the publication.

\section{Funding}

This work was supported by the National Natural Science Foundation of China $(81,400,224,81,300,203)$ and the Zhejiang Medical Science \& Technology Project (2015KYA071).

\section{Authors' contributions}

$Y Z$ and $Y W$ are the primary authors who were responsible for study design. YW and WX collected data. $\mathrm{CH}, \mathrm{HY}$ and WZ analyzed the data and drafted the manuscript. All authors revised and approved the final version for publication.

\section{Competing interests}

The authors declare that they have no competing interests.

Ethics approval and consent to participate

Ethical approval was not applicable for this systematic review and meta-analysis.

\section{Publisher's Note}

Springer Nature remains neutral with regard to jurisdictional claims in published maps and institutional affiliations.

\section{Author details}

'Department of Cardiology, The First Affiliated Hospital, Zhejiang University, School of Medicine, 79 Qingchun Road, Zhejiang, Hangzhou 310003, China. ${ }^{2}$ Department of Cardiology, Ningbo Medical Treatment Center Lihuili Hospital, Ningbo 315000, China. ${ }^{3}$ Department of Endocrinology, The First Affiliated Hospital, Zhejiang University, School of Medicine, 79 Qingchun Road, Hangzhou 310003, China.

Received: 24 October 2016 Accepted: 25 May 2017

Published online: 15 June 2017

\section{References}

1. O'Gara PT, Kushner FG, Ascheim DD, Casey DE Jr, Chung MK, de Lemos JA, et al. 2013 ACCF/AHA guideline for the management of ST-elevation myocardial infarction: executive summary: a report of the American College of Cardiology Foundation/American Heart Association Task Force on Practice Guidelines: developed in collaboration with the American College of Emergency Physicians and Society for Cardiovascular Angiography and Interventions. Catheter Cardiovasc Interv. 2013;82(1):E1-27.

2. Gurbel PA, Bliden KP, Hiatt BL, O'Connor CM. Clopidogrel for coronary stenting: response variability, drug resistance, and the effect of pretreatment platelet reactivity. Circulation. 2003;107(23):2908-13.

3. Kereiakes DJ, Gurbel PA. Peri-procedural platelet function and platelet inhibition in percutaneous coronary intervention. JACC Cardiovasc Interv. 2008;1(2):111-21.

4. Sibbing D, Braun S, Morath T, Mehilli J, Vogt W, Schomig A, et al. Platelet reactivity after clopidogrel treatment assessed with point-of-care analysis and early drug-eluting stent thrombosis. J Am Coll Cardiol. 2009;53(10):849-56. 
5. Siller-Matula JM, Trenk D, Schror K, Gawaz M, Kristensen SD, Storey RF, et al. Response variability to P2Y12 receptor inhibitors: expectations and reality. JACC Cardiovasc Interv. 2013;6(11):1111-28.

6. Bonello L, Tantry US, Marcucci R, Blindt R, Angiolillo DJ, Becker R, et al. Consensus and future directions on the definition of high on-treatment platelet reactivity to adenosine diphosphate. J Am Coll Cardiol. 2010;56(12):919-33.

7. Parodi G, Marcucci R, Valenti R, Gori AM, Migliorini A, Giusti B, et al. High residual platelet reactivity after clopidogrel loading and long-term cardiovascular events among patients with acute coronary syndromes undergoing PCI. JAMA. 2011;306(11):1215-23.

8. Bonello L, Camoin-Jau L, Arques S, Boyer C, Panagides D, Wittenberg O, et al. Adjusted clopidogrel loading doses according to vasodilator-stimulated phosphoprotein phosphorylation index decrease rate of major adverse cardiovascular events in patients with clopidogrel resistance: a multicenter randomized prospective study. J Am Coll Cardiol. 2008;51(14):1404-11.

9. Bonello L, Camoin-Jau L, Armero S, Com O, Arques S, Burignat-Bonello C, et al. Tailored clopidogrel loading dose according to platelet reactivity monitoring to prevent acute and subacute stent thrombosis. Am J Cardiol. 2009;103(1):5-10.

10. Mayer K, Schulz S, Bernlochner I, Morath T, Braun S, Hausleiter J, et al. A comparative cohort study on personalised antiplatelet therapy in $\mathrm{PCl}$ treated patients with high on-clopidogrel platelet reactivity. Results of the ISAR-HPR registry. Thromb Haemost. 2014;112(2):342-51.

11. Price MJ, Berger PB, Teirstein PS, Tanguay JF, Angiolillo DJ, Spriggs D, et al. Standard- vs high-dose clopidogrel based on platelet function testing after percutaneous coronary intervention: the GRAVITAS randomized trial. JAMA. 2011;305(11):1097-105

12. Collet JP, Cuisset T, Range G, Cayla G, Elhadad S, Pouillot C, et al. Bedside monitoring to adjust antiplatelet therapy for coronary stenting. N Engl J Med. 2012;367(22):2100-9.

13. Trenk D, Stone GW, Gawaz M, Kastrati A, Angiolillo DJ, Muller U, et al. A randomized trial of prasugrel versus clopidogrel in patients with high platelet reactivity on clopidogrel after elective percutaneous coronary intervention with implantation of drug-eluting stents: results of the TRIGGER-PCI (Testing Platelet Reactivity In Patients Undergoing Elective Stent Placement on Clopidogrel to Guide Alternative Therapy With Prasugrel) study. J Am Coll Cardiol. 2012;59(24):2159-64.

14. Cayla G, Cuisset T, Silvain J, Leclercq F, Manzo-Silberman S, Saint-Etienne C, et al. Platelet function monitoring to adjust antiplatelet therapy in elderly patients stented for an acute coronary syndrome (ANTARCTIC): an openlabel, blinded-endpoint, randomised controlled superiority trial. Lancet. 2016;388(10055):2015-22

15. Steiner $\mathrm{S}$, Moertl D. Platelet reactivity tests for assessing antiplatelet drug response: what the clinician needs to know. Expert Rev Cardiovasc Ther. 2013;11(8):975-84.

16. Gorog DA, Fuster V. Platelet function tests in clinical cardiology: unfulfilled expectations. J Am Coll Cardiol. 2013:61(21):2115-29.

17. Aradi D, Storey RF, Komocsi A, Trenk D, Gulba D, Kiss RG, et al. Expert position paper on the role of platelet function testing in patients undergoing percutaneous coronary intervention. Eur Heart J. 2014;35(4):209-15.

18. Rao AK, Pratt C, Berke A, Jaffe A, Ockene I, Schreiber TL, et al. Thrombolysis in Myocardial Infarction (TIMI) Trial-phase I: hemorrhagic manifestations and changes in plasma fibrinogen and the fibrinolytic system in patients treated with recombinant tissue plasminogen activator and streptokinase. J Am Coll Cardiol. 1988;11(1):1-11.

19. The GUSTO investigators. An international randomized trial comparing four thrombolytic strategies for acute myocardial infarction. N Engl J Med. 1993;329(10):673-82.

20. Montalescot G, White HD, Gallo R, Cohen M, Steg PG, Aylward PE, et al. Enoxaparin versus unfractionated heparin in elective percutaneous coronary intervention. N Engl J Med. 2006;355(10):1006-17.

21. Mehran R, Rao SV, Bhatt DL, Gibson CM, Caixeta A, Eikelboom J, et al. Standardized bleeding definitions for cardiovascular clinical trials: a consensus report from the Bleeding Academic Research Consortium. Circulation. 2011;123(23):2736-47.

22. Higgins JP, Altman DG, Gotzsche PC, Juni P, Moher D, Oxman AD, et al. The Cochrane Collaboration's tool for assessing risk of bias in randomised trials. BMJ. 2011;343:d5928.

23. Aleil B, Jacquemin L, De Poli F, Zaehringer M, Collet JP, Montalescot G, et al. Clopidogrel $150 \mathrm{mg} /$ day to overcome low responsiveness in patients undergoing elective percutaneous coronary intervention: results from the VASP-02 (Vasodilator-Stimulated Phosphoprotein-02) randomized study. JACC Cardiovasc Interv. 2008;1(6):631-8.
24. Tousek P, Osmancik P, Paulu P, Kocka V, Widimsky P. Clopidogrel uptitration versus standard dose in patients with high residual platelet reactivity after percutaneous coronary intervention: a single-center pilot randomised study. Int J Cardiol. 2011;150(2):231-2.

25. Wang XD, Zhang DF, Zhuang SW, Lai Y. Modifying clopidogrel maintenance doses according to vasodilator-stimulated phosphoprotein phosphorylation index improves clinical outcome in patients with clopidogrel resistance. Clin Cardiol. 2011;34(5):332-8.

26. Aradi D, Rideg O, Vorobcsuk A, Magyarlaki T, Magyari B, Konyi A, et al. Justification of $150 \mathrm{mg}$ clopidogrel in patients with high on-clopidogrel platelet reactivity. Eur J Clin Investig. 2012;42(4):384-92

27. Ari H, Ozkan H, Karacinar A, Ari S, Koca V, Bozat T. The EFFect of hlgh-dose Clopldogrel treatmENT in patients with clopidogrel resistance (the EFFICIENT trial). Int J Cardiol. 2012;157(3):374-80

28. Hazarbasanov D, Velchev V, Finkov B, Postadjian A, Kostov E, Rifai N, et al. Tailoring clopidogrel dose according to multiple electrode aggregometry decreases the rate of ischemic complications after percutaneous coronary intervention. J Thromb Thrombolysis. 2012;34(1):85-90.

29. Collet JP, Cayla G, Cuisset T, Elhadad S, Range G, Vicaut E, et al. Randomized comparison of platelet function monitoring to adjust antiplatelet therapy versus standard of care: rationale and design of the assessment with a double randomization of (1) a fixed dose versus a monitoring-guided dose of aspirin and clopidogrel after DES implantation, and (2) treatment interruption versus continuation, 1 year after stenting (ARCTIC) study. Am Heart J. 2011;161(1):5-12.e15.

30. Samardzic J, Krpan M, Skoric B, Pasalic M, Petricevic M, Milicic D. Serial clopidogrel dose adjustment after platelet function testing improves outcome of acute coronary syndrome patients undergoing percutaneous coronary intervention with high on-treatment platelet reactivity. J Thromb Thrombolysis. 2014;38(4):459-69.

31. Smith SC Jr, Feldman TE, Hirshfeld JW Jr, Jacobs AK, Kern MJ, King SB, et al. ACC/AHA/SCAI 2005 guideline update for percutaneous coronary intervention: a report of the American College of Cardiology/American Heart Association Task Force on Practice Guidelines (ACC/AHA/SCAI Writing Committee to Update 2001 Guidelines for Percutaneous Coronary Intervention). Circulation. 2006;113(7):e166-286.

32. Jeong YH, Lee SW, Choi BR, Kim IS, Seo MK, Kwak CH, et al. Randomized comparison of adjunctive cilostazol versus high maintenance dose clopidogrel in patients with high post-treatment platelet reactivity: results of the ACCEL-RESISTANCE (Adjunctive Cilostazol Versus High Maintenance Dose Clopidogrel in Patients With Clopidogrel Resistance) randomized study. J Am Coll Cardiol. 2009;53(13):1101-9.

33. Campo G, Fileti L, Valgimigli M, Tebaldi M, Cangiano E, Cavazza C, et al. Poor response to clopidogrel: current and future options for its management. J Thromb Thrombolysis. 2010;30(3):319-31.

34. Campo G, Miccoli M, Tebaldi M, Marchesini J, Fileti L, Monti M, et al. Genetic determinants of on-clopidogrel high platelet reactivity. Platelets. 2011;22(6):399-407.

35. Fileti L, Campo G, Valgimigli M. Latest clinical data on testing for high ontreatment platelet reactivity. Rev Cardiovasc Med. 2011;12(Suppl 1):S14-22.

36. Reny JL, Fontana P, Hochholzer W, Neumann FJ, Ten Berg J, Janssen PW, et al. Vascular risk levels affect the predictive value of platelet reactivity for the occurrence of MACE in patients on clopidogrel. Systematic review and metaanalysis of individual patient data. Thromb Haemost. 2016;115(4):844-55.

37. Aradi D, Komocsi A, Price MJ, Cuisset T, Ari H, Hazarbasanov D, et al. Efficacy and safety of intensified antiplatelet therapy on the basis of platelet reactivity testing in patients after percutaneous coronary intervention: systematic review and meta-analysis. Int J Cardiol. 2013;167(5):2140-8.

38. Xu L, Hu XW, Zhang SH, Li JM, Zhu H, Xu K, et al. Intensified Antiplatelet Treatment Reduces Major Cardiac Events in Patients with Clopidogrel Low Response: A Meta-analysis of Randomized Controlled Trials. Chin Med J. 2016;(8):129, 984-991.

39. Stone GW, Witzenbichler B, Weisz G, Rinaldi MJ, Neumann FJ, Metzger DC, et al. Platelet reactivity and clinical outcomes after coronary artery implantation of drug-eluting stents (ADAPT-DES): a prospective multicentre registry study. Lancet. 2013:382(9892):614-23.

40. Alexopoulos D, Galati A, Xanthopoulou I, Mavronasiou E, Kassimis G, Theodoropoulos KC, et al. Ticagrelor versus prasugrel in acute coronary syndrome patients with high on-clopidogrel platelet reactivity following percutaneous coronary intervention: a pharmacodynamic study. J Am Coll Cardiol. 2012;60(3):193-9. 
41. Aradi D, Tornyos A, Pinter T, Vorobcsuk A, Konyi A, Falukozy J, et al. Optimizing P2Y12 receptor inhibition in patients with acute coronary syndrome on the basis of platelet function testing: impact of prasugrel and high-dose clopidogrel. J Am Coll Cardiol. 2014;63(11):1061-70.

42. Dridi NP, Johansson PI, Clemmensen P, Stissing T, Radu MD, Qayyum A, et al. Prasugrel or double-dose clopidogrel to overcome clopidogrel lowresponse-the TAILOR (Thrombocytes And IndividuaLization of ORal antiplatelet therapy in percutaneous coronary intervention) randomized trial. Platelets. 2014;25(7):506-12.

43. Motoda C, Ueda H, Hayashi Y, Toyofuku M, Okimoto T, Otsuka M, et al. Impact of platelet reactivity to adenosine diphosphate before implantation of drug-eluting stents on subsequent adverse cardiac events in patients with stable angina. Circ J. 2012;76(3):641-9.

44. Bagai A, Peterson ED, McCoy LA, Effron MB, Zettler ME, Stone GW, et al. Association of measured platelet reactivity with changes in P2Y12 receptor inhibitor therapy and outcomes after myocardial infarction: Insights into routine clinical practice from the TReatment with ADP receptor iNhibitorS: Longitudinal Assessment of Treatment Patterns and Events after Acute Coronary Syndrome (TRANSLATE-ACS) study. Am Heart J. 2017;187:19-28.

45. Lee SW, Park SW, Kim YH, Yun SC, Park DW, Lee CW, et al. Drug-eluting stenting followed by cilostazol treatment reduces late restenosis in patients with diabetes mellitus the DECLARE-DIABETES Trial (A Randomized Comparison of Triple Antiplatelet Therapy with Dual Antiplatelet Therapy After Drug-Eluting Stent Implantation in Diabetic Patients). J Am Coll Cardiol. 2008:51(12):1181-7.

46. Lee SW, Park SW, Kim YH, Yun SC, Park DW, Lee CW, et al. A randomized, double-blind, multicenter comparison study of triple antiplatelet therapy with dual antiplatelet therapy to reduce restenosis after drug-eluting stent implantation in long coronary lesions: results from the DECLARE-LONG II (Drug-Eluting Stenting Followed by Cilostazol Treatment Reduces Late Restenosis in Patients with Long Coronary Lesions) trial. J Am Coll Cardiol. 2011;57(11):1264-70.

47. Patil SB, Jackman LE, Francis SE, Judge HM, Nylander S, Storey RF. Ticagrelor effectively and reversibly blocks murine platelet P2Y12-mediated thrombosis and demonstrates a requirement for sustained P2Y12 inhibition to prevent subsequent neointima. Arterioscler Thromb Vasc Biol. 2010;30(12):2385-91.

48. Breet NJ, van Werkum JW, Bouman HJ, Kelder JC, Ruven HJ, Bal ET, et al. Comparison of platelet function tests in predicting clinical outcome in patients undergoing coronary stent implantation. JAMA. 2010;303(8):754-62.

\section{Submit your next manuscript to BioMed Central and we will help you at every step:}

- We accept pre-submission inquiries

- Our selector tool helps you to find the most relevant journal

- We provide round the clock customer support

- Convenient online submission

- Thorough peer review

- Inclusion in PubMed and all major indexing services

- Maximum visibility for your research

Submit your manuscript at www.biomedcentral.com/submit

) Biomed Central 